\title{
운동사(運動師) 양성을 위한 대학 교과과정 구성의 기본방향*
}

\begin{abstract}
Jung Sok Oak. Basic Directions of Curriculum Development for Educating Kinesiologists in University. KINESIOLOGY, 2016, 18(1): 47-57. [PURPOSE] This study aims to understand types of business seeking kinesiologists and its job details, investigate types of qualification systems and job details of similar areas in Korea and other countries, and suggest basic directions for future curricular development for training kinesiologists through an analysis of kinesiologist-developing university curricular. [METHODS] Basic data were collected from homepages. Frequency analysis $(a=05)$ was employed for data analysis of employer's job posting in the web site of Korean Association of certified Exercise Professionals. Delphi method that 9 experts participated for decision-making was used for specific contents. [RESULTS] First, health and medical institutions sought for kinesiologists more than sports related facilities. Clinics put the most help-wanted advertisement. Second, the job duties needed for kinesiologist were mostly rehabilitation exercise for patients with muscular-skeletal injuries followed by health fitness and clinical exercise. But it was identified that Korean national license for Health/Fitness Instructor legally prohibits the body alignment exercise and rehabilitation training, and the period of occupational training is very long. Third, there were twelve different sport major departments in Korea that were for training kinesiologists. The curricular in these departments were not systematic for training highly qualitied specialists. Results also showed that the titles of classes were not identical. They were heavily weighted to the health fitness area. Experiment practice and field exercise were not performed actively. [CONCLUSIONS] In order to train trustful and highly professional kinesiologists, universities must consider revisions in curricular in the following directions. First, they need to develop a field-centered curriculum in which the practical competence of kinesiologist can be cultivated. Second, the classes which are commonly important to kinesiologists' role performing need to be required common subjects. Third, subjects in which students can build basic medical knowledge should be required classes. Fourth, subjects such as evaluation of sports injury, therapeutic exercise, rehabilitation exercise and practicum should be reenforced. If all these curricular suggestions can be implemented, basically it is important that there should be a guidelines for the Korean and English titles of classes and practicum.
\end{abstract}

Key words : kinesiology, kinesiologist, curriculum 주요어 : 운동학, 운동사, 교육과정

\section{서론}

운동의 효과가 알려지면서 건강체력 증진과 손상 (損傷) 예방 및 재활 등의 목적을 가진 운동 수요가 늘어나고 운동사(運動師)의 역할이 증대되었지만, 대 학의 교육과정이 체계적으로 정비되지 않아 문제가 되고 있다.

정보화 사회에서 운동사는 건강인과 환자 또는 운 동선수들의 성, 연령, 생활습관, 건강상태, 이학적(理 學的) 정보와 체력 정보를 통합적으로 고려한 적극적
인 서비스 활동(Jung, 2013)을 요구받고 있다. 또한 이 같은 사회적 요구에 부응하기 위해서 상당한 수의 대 학들이 운동사 양성을 목표로 하고 있으며, 대한운동 교육평가원에서는 운동사자격시험을 시행하고 자격증 을 발급하고 있다. 그러나 운동사 자격을 취득하고자 하는 많은 학생들이 해당 대학의 대학교육을 이수하 였음에도 불구하고 대학재학 중 또는 대학졸업 후 운 동사자격시험에 응시하기 위하여 운동사 자격연수를 받는 경우가 많다.

이 같은 상황은 많은 대학들이 교육목표를 충족할

* 이 연구는 2014학년도 단국대학교 대학연구비 지원으로 연구되었음.

** 교신저자. kacep2001@hanmail.net 
수 있는 교과과정이 정비돼 있지 못한 연유에서 비롯 된 것으로 이를 개선하기 위해서는 운동사의 업무범 위와 직무내용 구체화하고 이에 적합한 교육내용을 구성하는 일이 중요하다.

그러므로 이 연구는 첫째, 운동사를 찾는 업장의 유 형과 업무내용을 파악하고 둘째, 국내외 유사자격제도의 자격유형과 직무내용을 조사하며, 셋째, 국내 운동사 관 련 대학의 교과과정을 분석하여 운동사 양성을 위한 대 학의 교과과정 구성의 기본방향을 제시하고자 하였다.

이 같은 작업은 국내 운동사 관련 대학의 교과과정 을 개선하는데 도움을 줄 수 있을 뿐만 아니라 급속 히 퍼져 가는 한류 속에서 2016년에 아시아운동학회 가 창립되고 운동사의 개념을 아시아 전역으로 확산 시킬 수 있는 기회를 맞아 한국의 운동사 위상을 높 이고 취업시장을 넓히는 지름길이 될 것이다.

\section{연구방법}

이 연구에서 채택한 연구방법은 대한운동사협회 (Korean Association of Certified Exercise Professionals, $\mathrm{KACEP}$ ) 및 해당기관의 홈페이지를 통하여 기초자료 를 조사하였고 이들 자료를 분류하거나 처리하는 하 는데 있어서 Delphi 기법을 활용하였다. Delphi 기법 에서는 연구과제별 설문의 반복 수행을 통해 의견의 이견(異見)을 공유하고, 그 의견에 대한 자신의 의견 을 자유롭게 주장하여 서로 상반된 의견을 교환하고 피드백시킴으로써, 전체 패널들의 델파이 본래 목적의 합의 도출에 충실할 수 있도록 진행하였다. Delphi 기 법에서의 패널선정은 운동사자격제도에 관한 9 인의 전문가(운동사 관련 학과 교수 5 인, 박사급 운동사 4 인)로 구성하였다.

\section{구인광고에 나타난 업종과 업무내용 분석}

2014년 11월 1일부터 2015년 9월 30일까지 대한운 동사협회 홈페이지의 구인광고 901건을 통해 구인광고 기관의 업종유형을 분류하고 구인광고 내용을 자료화 하여 빈도 분석을 하였으며 유의수준은 .05 로 하였다.
Delphi에서의 1차 설문지는 완전 개방형으로 패널에 의해 구인광고 요구한 단체나 기관의 업종과 성격을 분석하여 분류 하도록 하였다. 그 다음 1 차 설문지를 통해 분류된 항목을 2 차 구조화된 설문지를 통하여 최 종 구인요구 단체나 기관의 업종과 성격을 분석하였다.

앞서 분류된 구인기관의 업종과 성격을 토대로, 구 인광고에서 요구한 운동사의 세부적 임무와 직무를 분석하였다. 이 또한 Delphi에서의 1 차 설문지는 완전 개방형으로 패널에 의해 구인광고에서 요구한 세부적 임무와 업무 분석을 하도록 하였다. 그 다음 1 차 설문 지를 통해 분류된 항목을 2차 구조화된 설문지를 통 하여 최종 구인광고에서 요구한 세부적 임무와 업무 를 분석하였다.

\section{국내외 유사 자격제도의 업무내용 분석}

운동사와 유사한 국내외 자격제도는 한국의 건강운 동관리사, 그리고 미국의 American College of Sports Medicine(ACSM), National Athletic Trainer's Association(NATA), National Strength and Conditioning Association(NSCA) 등의 단체에서 발급 하는 자격들의 업무내용을 홈페이지를 통하여 조사, 분석하였다. 그 결과는 Delphi 기법에서의 패널로 참 가한 9 인의 전문가들에 의해 확정되었다.

\section{국내 운동사 양성 대학의 교과과정 분석}

이 연구의 대상 학과는, 국내 대학들의 웹 사이트를 통해 각 대학의 학과 명칭과 교육과정 등을 살펴 본 후 Delphi 기법에 의한 9 인의 전문가 회의를 통해 선 정하였다. 선택된 대학을 대상으로 1 차 완전 개방형 설 문지를 통해 교과과정을 1 차적으로 분류한 다음, 2 차로 구조화된 설문지를 통하여 교과과정을 분석 하였다.

각 대학의 교과과정의 분야는 건강체력 분야ffield of health fitness), 임상운동 분야(field of clinical exercise), 운동손상 분야(field of sport rehabilitation)로 구분하기 로 하였고, 교과목의 분류 기준은 다음과 같다.

건강체력 분야는, 운동학의 전 분야에 걸친 기초 과 목과 기본 이수 과목으로 건강체력 관리 운동전문가로 
서의 자질을 함양하고 실무에서 필요한 이론과 실기능 력을 갖추는데 필요한 교과목 등으로 분류하였다.

임상운동 분야는, 일반인과 질환자를 대상으로 운 동기능검사 및 처방, 평가를 토대로 각 개인의 체력과 의학적 상태를 고려하여 운동프로그램을 계획 및 평 가하고, 과학적인 근거를 바탕으로 운동을 지도하는데 필요한 교과목 등으로 분류하였다.

운동손상 분야는 일반인, 선수, 근골격계 질환이 있 는 환자를 대상으로 운동기능이나 손상을 평가하고, 다양한 도구와 장비를 이용하여 재활운동 프로그램을 작성하고 적절한 재활운동을 지도하는데 필요한 교과 목 등으로 분류하였다.

\section{결과}

\section{운동사 구인처 및 요구되는 업무내용}

대한운동사협회 홈페이지 구인광고를 11 개월간 (2014.11-2015.9.30)에 걸쳐 분석한 결과는 <Table 1> 과 같다.

Table 1. The Types of Employer's Job Posting in the Website of KACEP(2014-2015)

\begin{tabular}{|c|c|c|}
\hline Classification & $\mathrm{N}$ & $\%$ \\
\hline Sport related facilities & $(391)$ & $(43.40)$ \\
\hline Health/Fitness Center & 125 & 13.87 \\
\hline Enterprise Type Health/Fitness Center & 203 & 22.53 \\
\hline Sport Rehabilitation Center & 51 & 5.66 \\
\hline Others & 12 & 1.34 \\
\hline Clinical Settings & $(510)$ & $(56.60)$ \\
\hline Cinic & 276 & 30.63 \\
\hline Hospital & 135 & 14.98 \\
\hline Public Health & 50 & 5.55 \\
\hline Oriental Clinic/Hospital & 49 & 5.44 \\
\hline Total & 901 & 100.00 \\
\hline
\end{tabular}

운동사 구인은 순수 스포츠관련 시설(43.40\%)보다는 보건의료기관(56.60\%)에서 더 많은 운동사를 구인하고 있는 것으로 나타났다 $\left(x^{2}=15.65, p<0.05\right)$. 스포츠관련
시설 중에서는 개인이 하는 소형 운동시설 보다는 기 업형 헬스/피트니스 센터에서 운동사 구인이 많았다 $\left(x^{2}=218.50, p \times 0.05\right)$. 반면에 보건의료기관 중에서는 소 형병원(Clinic)에서 중대형 병원이나 보건소, 한의원 등 에서보다 운동사 구인을 많이 한 것으로 나타났다. 전 체적으로도 소형병원이 운동사 구인빈도가 가장 높았 다 $\left(x^{2}=268.83, p \times 0.05\right)$.

구인처 유형에 관계없이 운동사 등에게 요구되는 업무영역을 조사한 결과는 <Table 2>와 같다.

Table 2. Domains of Kinesiologist's Job Tasks Required in Employer's Job Posting of KACEP Website

\begin{tabular}{lrr}
\hline \multicolumn{1}{c}{ Field } & $\mathrm{N}$ & \multicolumn{1}{c}{$\%$} \\
\hline \hline Health/Fitness & 235 & 26.08 \\
Clinical Exercise & 76 & 8.44 \\
Sport Rehabilitation & 556 & 61.71 \\
Others & 34 & 3.77 \\
\hline \multicolumn{1}{r}{ Total } & 901 & 100.00 \\
\hline
\end{tabular}

운동사를 구인하면서 건강체력 관리 업무를 요구하 는 곳은 전체적으로 $26.08 \%$ 이었고, 임상운동 분야는 $8.44 \%$ 에 불과한 반면 스포츠재활(근골격계 손상관리) 업무를 요구하는 곳은 $61.70 \%$ 로서 가장 높은 비율을 차지하였다. 결과적으로 작금에 운동사의 업무는 운동 손상관리를 위한 스포츠재활 업무가 가장 많이 요구 되고 있음을 알 수 있었다 $\left(x^{2}=747.36, p<0.05\right)$.

\section{국 - 내외 운동사 유사 자격의 업무내용}

국내·외 운동사 유사자격제도의 업무내용을 분석 하기 위하여 문화체육관광부의 건강운동관리사 및 ACSM(American College of Sports Medicine, 2015), NATA(National Athletic Trainers Association, 2015), NSCA(National Strength \& Conditioning Association, 2015) 등에서 발급하는 자격증의 업무내용을 비교, 분 석하였다.

한국의 건강운동관리사 업무내용

2015년부터 시행 된 건강운동관리사는 "개인의 건 강상태와 체력을 평가하고 개인의 특성에 적합한 체 
력향상, 건강증진, 재활운동을 위한 상담, 운동의 계 획, 운동지도, 운동감독, 운동평가 등에 관한 복합적이 고 과학적인 운동교육 및 기능 업무"(Ministry of Culture, Sports and Tourism, 2014)를 수행할 수 있 게 되었다. 다만, "의사에 의한 의학적 검진 결과 치 료와 병행하여 건강증진 및 합병증 예방 등을 위한 운동이 필요하다고 의사가 인정하는 사람에 대해서는 의사의 의뢰(「의료기사 등에 관한 법률 시행령」제2 조 제1항 제 3호의 신체교정운동 및 재활훈련은 제외 한다)를 받아 업무를 수행 한다"(Ministry of Culture, Sports and Tourism, 2014)라고 되어있다.

Table 3. Job Tasks of Korean Health/Fitness Instructor

\begin{tabular}{|c|c|}
\hline Mission & Dimension of Tasks \\
\hline $\begin{array}{l}\text { Evaluation of } \\
\text { health and } \\
\text { physical fitness }\end{array}$ & $\begin{array}{l}\text { Testing and evaluating of health and } \\
\text { physical fitness }\end{array}$ \\
\hline $\begin{array}{l}\text { Evaluation of } \\
\text { exercise function }\end{array}$ & Testing and evaluating the health function \\
\hline $\begin{array}{l}\text { Development of } \\
\text { exercise } \\
\text { program }\end{array}$ & $\begin{array}{l}\text { Based on each testing, designing an exercise } \\
\text { program that considers the individual's } \\
\text { unique physical fitness characteristics }\end{array}$ \\
\hline $\begin{array}{l}\text { Management of } \\
\text { exercise }\end{array}$ & $\begin{array}{l}\text { Managing the exercise program to best } \\
\text { help each individual and to achieve } \\
\text { each individual's specific fitness goals }\end{array}$ \\
\hline $\begin{array}{l}\text { Education and } \\
\text { counseling }\end{array}$ & $\begin{array}{l}\text { Improving physical fitness and physical } \\
\text { function, by educating and counseling } \\
\text { each individual about exercise and the } \\
\text { practice of physical fitness }\end{array}$ \\
\hline $\begin{array}{l}\text { Exercise } \\
\text { guidance }\end{array}$ & $\begin{array}{l}\text { Training and assisting the individual in } \\
\text { performing the activities which comprise } \\
\text { the exercise program }\end{array}$ \\
\hline
\end{tabular}

Business planning/manag Consulting, implementing, and assessing ing/evaluating exercise businesses within a community

Ministry of Culture, Sports and Tourism (2013)

※ The reform plan for physical education leader qualifications seminar $\lrcorner$ Research results from a public hearing held Sep. 5, 2013

<Table 3>에서 보는 바와 같이 건강운동관리사의 업무 내용은, 건강 및 체력 평가, 운동기능 평가, 운동 프로그램 개발, 운동교육 및 상담, 운동지도, 운동사업
기획, 운영, 평가는 거의 대부분 건강체력 관리 분야 에 포함된 것들로 구성되어 있다. 반면에, 일반인과 질환자를 대상으로 하는 운동검사 및 평가, 운동지도 및 교육과 관련된 임상운동 분야와 손상 및 질병의 응급관리능력, 손상 및 질병의 병리학적 이해, 손상 평가 및 재활, 치료적 운동의 적용 등과 같은 운동손 상 분야의 내용이 상대적으로 적었다.

\section{미국의 운동사 유사 자격제도와 업무내용}

<Table 4>에서 보는 바와 같이 ACSM의 경우 건 강체력 분야 및 임상 분야와 함께 최근 특수 분야의 자격제도를 운영하고 있다.

$\mathrm{ACSM}$ 의 건강체력 분야 자격은, 주로 개인운동 지 도, 그룹운동 지도를 도맡아 하는 역할을 수행하고 있 다. 그리고 의학적인 통제가 가능한 질환자나 일반인 을 대상으로 체력평가와 컨디셔닝을 통하여 건강체력 수준을 향상시키는데 기여하고 있다.

$\mathrm{ACSM}$ 의 임상 분야 자격은 임상운동 분야에 해당 되며, 대사질환자, 심혈관질환자, 폐질환자 등을 대상 으로 운동관련 상담, 운동지도 및 평가, 안전한 운동 프로그램 제공 등의 업무를 담당하고 있다.

$\mathrm{ACSM}$ 의 특수 분야의 자격으로는 “암 환자"를 위 한 운동사(CET), "건강한 라이프스타일을 위한 동기 부여와 안전하고 효과적인 프로그램을 지도하는" 운 동사(CIFT), "국가적, 사회적 차원에서의 신체활동 권 장"을 위한 공중보건 운동사(PAPHS)가 있었다.

$\mathrm{NSCA}$ 는 <Table 5 >에서 보는 바와 같이 개인운동 분야에 해당되는 네 가지 종류의 자격제도를 운영하 고 있다.

CPT(NSCA Certified Personal Trainers)는 ACSM 의 CPT(ACSM Certified Personal Trainers) 및 GEI(ACSM Certified Group Exercise Instructors) 업 무와 유사하다. 그 업무 내용을 살펴보면, 건강 및 체 력에 대한 교육 및 훈련, 운동 교육 및 훈련, 안전하 고 효과적인 프로그램 설계 및 제공 등을 주로 하는 건강체력 전문가라고 할 수 있다.

반면 CSCS(Certified Strength and Conditioning Specialists)는 CPT보다 좀 더 적극적인 업무 내용을 포함하고 있다. 예들 들면, 선수들을 양성하기 위하 과학적인 지식을 적용하거나 선수들을 위한 안전하고 
효과적인 강도의 훈련과 컨디셔닝 프로그램을 제공한 다. 또한 영양 및 부상 예방과 관련된 지침을 제공하 기도 한다.

CSPSs(Certified Special Population Specialists)는 $\mathrm{ACSM}$ 의 CEP나 RCEP와 업무내용에서 많은 부분이 서로 다르지만 특별한 인구 집단의 체력과 건강에 대 해 의료 전문가들과 협업하고 관리하는 전문가라는 점에서 공통점을 찾을 수 있다.

TSAC-F(Tactical Strength and Conditioning Facilitators) 는 군인, 소방관이나 구조대원, 법집행인, 응급요원들 의 질환이나 손상예방, 건강증진, 수행능력 향상을 책 임지는 전문가들이다.

한편, NATA-ATC(Athletic Trainer Certified)는 그 업무 내용이 운동손상 관리에 포커스가 맞추어져 있 다. 그들은 운동현장, 일상생활과 일터에서 환자와 고
객의 활동과 참여를 최적화하기 위하여 의사들과 협 력하고 있다. NATA-ATC들은 장애, 기능적 제한 등 을 최소화하기 위해 의학적인 처치와 만성근신경계 불편함, 급성 및 아급성 재활, 치료, 진단, 검사, 예방 을 포함하는 일련의 내용을 교육받고 있다. <Table 6>에서 알 수 있듯이 NATA-ATC 들은 RDS(Role Delineation Study) 이라는 5가지 업무 즉, (1) 건강증 진과 손상 및 질병 예방, (2) 임상 평가 및 진단, (3) 응급 치료, (4) 처치 및 재활, (5) 조직이나 특별한 집 단의 건강과 웰빙 등을 다루고 있는 것이다.

\section{국내 운동사 관련 대학의 교과과정}

이 연구에 참가한 9인의 전문가들이 Delphi 기법을 통해 운동사 양성 대학으로 선정한 대학은 12 개 대학

Table 4. Classification of ACSM Certifications(ACSM, 2015)

\begin{tabular}{|c|c|c|}
\hline Trek & Certification & Dimension of Tasks \\
\hline \multirow{3}{*}{$\begin{array}{l}\text { Health Fitness } \\
\text { Certifications }\end{array}$} & $\begin{array}{l}\text { Personal Trainers }{ }^{\circledR} \\
\text { (CPT) }\end{array}$ & $\begin{array}{l}\text { ACSM Certified Personal Trainers }{ }^{\circledR}(\mathrm{CPT}) \text { are at the front line of the health fitness } \\
\text { movement - and use research-based techniques to help people of all fitness levels } \\
\text { reach their personal fitness goals. }\end{array}$ \\
\hline & $\begin{array}{l}\text { Group Exercise } \\
\text { Instructors }^{\circledR} \\
\text { (GEI) }\end{array}$ & $\begin{array}{l}\text { ACSM Certified Group Exercise Instructors }{ }^{\circledR} \text { (GEI) are at the forefront of the group exencise } \\
\text { movement. From coaching an individual through a tough session to providing healthy } \\
\text { lifestyle support outside of class - the personal impact you'll make is long-lasting. }\end{array}$ \\
\hline & $\begin{array}{l}\text { Exercise } \\
\text { Physiologists } \\
\text { (EP-C) }\end{array}$ & $\begin{array}{l}\text { ACSM Certified Exercise Physiologists }{ }^{\circledR} \text { take training to an advanced level by } \\
\text { conducting and interpreting physical fitness assessments and developing exercise } \\
\text { prescriptions for people who are healthy or have medically controlled diseases. }\end{array}$ \\
\hline \multirow[b]{2}{*}{$\begin{array}{l}\text { Clinical } \\
\text { Certifications }\end{array}$} & $\begin{array}{l}\text { Clinical Exercise } \\
\text { Physiologists } \\
\text { (CEP) }\end{array}$ & $\begin{array}{l}\text { ACSM Certified Cinical Exercise Physiologists }{ }^{\circledR} \text { (CEP) provide exercise-related consulting, } \\
\text { and conduct assessments and individualized training to guide and strengthen the } \\
\text { lifestyles of those with cardiovascular, pulmonary, and metabolic diseases and disorders. }\end{array}$ \\
\hline & $\begin{array}{l}\text { Registered Clinical } \\
\text { Exercise Physiologist } \\
\text { (RCEP). }\end{array}$ & $\begin{array}{l}\text { ACSM Registered Clinical Exercise Physiologist }{ }^{\circledR} \text { (RCEP). Field-experienced and } \\
\text { highly educated, ACSM RCEPs are prepared to work in collaboration with a } \\
\text { clinical or research team that oversees exercise programming in individuals } \\
\text { experiencing a state of disease or who are physically limited. An ACSM RCEP } \\
\text { impacts individuals' quality of life on a daily basis. }\end{array}$ \\
\hline \multirow{3}{*}{$\begin{array}{l}\text { Specialty } \\
\text { Certifications }\end{array}$} & $\begin{array}{l}\text { Certified Inclusive } \\
\text { Fitness Trainers (CIFT }\end{array}$ & $\begin{array}{l}\text { ACSM/NCHPAD CIFTs create adapted programming that promotes safe and } \\
\text { effective training - while also providing motivational support for a healthy lifestyle }\end{array}$ \\
\hline & $\begin{array}{l}\text { Cancer Exercise } \\
\text { Trainer (CET) }\end{array}$ & $\begin{array}{l}\text { ACSM/ACS Certified Cancer Exercise Trainers (CETs) design and administer fitness } \\
\text { assessments and exercise programs specific to a person's cancers diagnosis, } \\
\text { treatment, and current recovery status. }\end{array}$ \\
\hline & $\begin{array}{l}\text { Physical Activity in } \\
\text { Public Health } \\
\text { Specialist (PAPHS) }\end{array}$ & $\begin{array}{l}\text { ACSM and the National Physical Activity Society (NPAS) - learn how to make } \\
\text { your voice heard for the advancement of your community on the way to building } \\
\text { partnerships, developing initiatives, and advocating for programming that centers on } \\
\text { physical activity as a path to stronger public health }\end{array}$ \\
\hline
\end{tabular}


Table 5. Classification of NSCA Certifications(NSCA, 2015)

Certification

restied

Certified Strength and

Conditioning

Specialists (CSCSs)

Certified Strength and Conditioning Specialists (CSCSs) are professionals who apply scientific knowledge to train athletes for the primary goal of improving athletic performance. They conduct sport-specific testing sessions, design and implement safe and effective strength training and conditioning programs and provide guidance regarding nutrition and injury prevention.

Certified Special Population Specialists (CSPS) are fitness professionals who, using an individualized approach, assess, motivate, educate, and train special population clients of all ages regarding their

Certified Special health and fitness needs, preventively, and in collaboration with healthcare professionals. Special Population Specialists populations include those with chronic and temporary health conditions. CSPSs design safe and (CSPS) effective exercise programs, provide the guidance to help clients achieve their personal health/fitness goals, and recognize and respond to emergency situations. Recognizing their own areas of expertise, CSPSs receive referrals from and refer clients to other healthcare providers as appropriate.

NSCA-Certified

Personal Trainers

(NSCA-CPT ${ }^{\circledR}$ )

NSCA-Certified Personal Trainers (NSCA-CPT ${ }^{\circledR}$ ) are health/fitness professionals who, using an individualized approach, assess, motivate, educate and train clients regarding their personal health and fitness needs. A personal training certification will help to design safe and effective exercise programs, provide the guidance to help clients achieve their personal health/fitness goals and respond appropriately in emergency situations.

Tactical Strength and Conditioning Facilitators $\left(\right.$ TSAC-F ${ }^{\circledR}$ ) apply scientific knowledge to physically

Tactical Strength and train military, fire and rescue, law enforcement, protective services, and other emergency personnel Conditioning to improve performance, promote wellness, and decrease injury risk.

Facilitators (TSAC- $\mathrm{F}^{\mathrm{B}}$ ) They conduct needs analyses and physical testing sessions, design and implement safe and effective strength training and conditioning programs, and provide general information regarding nutrition.

체육계열학과였다.

<Table 7>에서 보는 바와 같이 12 개 대학의 운동 사 관련 학과의 교과과정을 분석한 결과 12 개 대학 모두가 개설하고 있는 교과목은 해부학이었으며, 그 다음으로 개설 빈도가 높은 과목은 스포츠심리학(11 개교), 운동생리학/운동역학/운동영양학(10개교), 건강 교육/트레이닝방법론/응급처치/운동손상예방및현장 실습(9개교), 체력측정평가/운동손상학/스포츠마시지
(8개교) 순으로 조사 대상 학과 중 $2 / 3$ 이상의 대학 이 이들 교과목을 개설하고 있었다. 웨이트트레이닝/ 대사성질환과운동/치료적운동(6개교) 등의 과목은 조 사대상 학교의 절반이 개설하고 있었다. 나머지 교과 목들은 각 대학마다 서로 상이한 교과목들이 개설되 고 전공과목 개설의 일관성을 찾기 힘들었다.

평균 3학점 이상 개설되고 있는 교과목들은 해부학, 스포츠심리학, 운동생리학, 특수체육, 운동생리학실험,

Table 6. Five domains of the Role Delineation Study(RDS) in NATA

\begin{tabular}{|c|c|c|}
\hline & Domains & The Role Delineation Study \\
\hline I & $\begin{array}{l}\text { Injury/illness prevention and } \\
\text { wellness protection }\end{array}$ & Educating participants and managing risk for safe performance and function \\
\hline$\Pi$ & Cinical evaluation and diagnosis & $\begin{array}{l}\text { Implementing standard evaluation techniques and formulating a clinical } \\
\text { impression for the determination of a course of action. }\end{array}$ \\
\hline III & Immediate and emergency care & $\begin{array}{l}\text { Employing standard care procedures and communicating outcomes for } \\
\text { efficient and appropriate care of the injured. }\end{array}$ \\
\hline IV & Treatment and rehabilitation & Reconditioning participants for optimal performance and function. \\
\hline $\mathrm{V}$ & $\begin{array}{l}\text { Organizational and professional } \\
\text { health and well-being }\end{array}$ & $\begin{array}{l}\text { Understanding and adhering to approved organizational and professional } \\
\text { practices and guidelines to ensure individual and organizational well-being. }\end{array}$ \\
\hline
\end{tabular}

Role Delineation Study. 6th ed. Omaha, NE: Board of Certification; 2009. 
Table 7. Curriculum Analysis of Sport Related Department in Twelve Universities(2015)

\begin{tabular}{|c|c|c|c|c|c|}
\hline Health Fitness & $\begin{array}{l}\text { Average } \\
\text { of time }\end{array}$ & $\begin{array}{l}\text { N. of } \\
\text { collage }\end{array}$ & Clinical Exercise & $\begin{array}{l}\text { Average } \\
\text { of time }\end{array}$ & $\begin{array}{l}\text { N. of } \\
\text { collage }\end{array}$ \\
\hline Human Anatomy & 4.2 & 12 & Measurement \& Eval. of Physical Fitness & 2.9 & 8 \\
\hline Sports Psychology & 3.1 & 11 & Metabolic Syndrome \& Exercise & 2.7 & 6 \\
\hline Exercise Physiology & 3.8 & 10 & Pathophysiology & 2.6 & 5 \\
\hline Sports Biomechanics & 2.8 & 10 & Graded Exercise Test & 4.8 & 5 \\
\hline Exercise Nutrition & 2.9 & 10 & Ex. Program Development \& Evaluation & 3.3 & 4 \\
\hline Health education & 2.7 & 9 & Electrocardiography & 27 & 4 \\
\hline Theory of training & 3.0 & 9 & Theory of the Aged Health & 2.3 & 4 \\
\hline First-AID \& CPR & 2.8 & 9 & Medical Terms & 20 & 3 \\
\hline Weight training & 2.8 & 6 & Medical Law & 3.0 & 2 \\
\hline Growth \& Development & 24 & 5 & Aerobic Exercises & 1.5 & 2 \\
\hline Theories in Adapted Physical Education & 3.4 & 5 & Flexibility Training & 0.5 & 2 \\
\hline Measurement \& EVAL of Human Performance & 2.3 & 5 & Cront Dolubilitation & Average & N. of \\
\hline Gymnastics & 1.5 & 4 & sport Renabilitation & of time & collage \\
\hline Physical education & 2.0 & 3 & Sports injury prevention \& on-site training & 12.4 & 9 \\
\hline Sports Sociology & 27 & 3 & The Principles of Athletic Training & 6.1 & 8 \\
\hline Advanced Exercise Physiology Laboratory & 3.3 & 3 & Sports Massage & 1.9 & 8 \\
\hline Exercise Biochemistry & 2.7 & 3 & Therapeutic Exercise & 6.4 & 6 \\
\hline Health education & 5.5 & 2 & Sports Taping & 2.3 & 5 \\
\hline Physical training & 2.5 & 2 & Yoga \& Pilates & 1.7 & 5 \\
\hline Health/fitness establishment & 3.0 & 2 & Chiropractic & 3.3 & 4 \\
\hline Exercise Teaching & 4.5 & 2 & Exercise With Props & 1.3 & 3 \\
\hline Sport Facility Management & 6.0 & 2 & Movement Analysis & 2.0 & 2 \\
\hline Method of Research in Sports Science & 3.0 & 2 & General Physics & 1.5 & 2 \\
\hline Theory of Leasure Recreation & 20 & 2 & Aqua Rehabilitation Exercise & 1.0 & 2 \\
\hline Sport Marketing & 2.0 & 2 & \multirow{3}{*}{ cf) Ex.: exercise, Eval.: evaluation } & & \\
\hline Theory of Motor learning & 3.0 & 2 & & & \\
\hline Introduction of Lifetime Sports & 3.0 & 2 & & & \\
\hline
\end{tabular}

* Twelve Universities: CHA University, Daegu University, Dankook University, Dongshin University, Jeonju University, Konyang University, Korea National Sport University, Kyunghee University, Namseoul University, Soonchunhyang University, Sungshin Women's University, Woosong University

건강교육, 체력육성, 운동지도론, 스포츠시설관리, 연구 법, 운동제어, 생활체육개론, 운동부하검사, 운동프로그 램개발평가, 의료법, 스포츠손상예방및현장실습, 운동 손상학, 치료적운동, 카이로프락틱 등의 과목이었다.

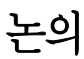

이 연구를 통해 운동사를 찾는 업장의 유형과 업무 내용을 파악하고, 국내외 유사자격제도의 자격유형과 직무내용을 조사하며, 국내 운동사 관련 대학의 교과 과정을 분석하여 운동사 양성을 위한 대학의 교과과 정 구성의 기본방향을 제시하고자 하였다.

이 연구의 결과 운동사를 구인하는 곳은 병원, 헬 스/피트니스센터 순으로 나타났지만 업장에서 요구하 는 업무영역은 근골격계 손상관리를 주로 하는 스포 
츠재활 업무를 요구하는 곳이 가장 많았고 그 다음 건강체력 관리, 임상운동 순으로 나타났다.

1999년 한국에서 임상운동사 자격제도를 시행하면 서 대형병원에서 심장재활 등 내과 환자들의 운동관 리 업무를 담당할 것으로 기대하였으나 대형병원의 스포츠의학센터는 크게 확산되지 못한 것 같다. 아울 러 중소병원에서도 내과 환자를 대상으로 하는 운동 서비스의 수요도 늘어나지 않은 것으로 보인다.

상대적으로 프로스포츠의 활성화로 인하여 운동선 수의 몸값이 올라가면서 운동선수의 건강관리나 부상 방지 및 재활에 관한 관심이 높아지면서 운동사에 대 한 인식이 많이 달라졌다. 아울러 사회적으로 근골격 계 질환관리 및 운동손상 관리를 위한 치료적 운동에 대한 인식이 높아졌다. 특히 정형외과나 재활의학과 등에서 이 같은 추세를 감안하여 스포츠재활 혹은 근 골격계 운동프로그램을 개설하게 된바 이 분야의 운 동사 수요가 늘어나 이 연구의 결과로 나타난 것이라 사료된다. 또한 이 같은 결과는, 시장에서 운동사에 대한 차별화된 기대는 일반적인 체력관리 수준을 넘 어서 근골격계 질환의 예방과 치료적 재활 운동 지도 인 것을 반영하는 것으로 사료된다.

결과적으로 임상운동사에 머물지 않고 운동사로서 건강체력 관리를 바탕으로 한 운동손상 관리 및 임상 운동 지도 등의 업무를 함께 담당할 수 있게끔 운동 사의 업무능력을 확장시킨 것은 올바른 판단이었다고 사료된다.

근골격계 질환 및 손상 관리를 주로 하는 치료적 운동 내지 재활 운동은 운동과정에서 운동사의 도움 이 많이 필요하고 일대일 지도가 기본이기 때문에 운 동사 수요가 대사성질환이나 그룹운동 지도에서보다 더 많이 나타날 수밖에 없다. 최근 건강체력 관리 분 야에서 개인운동 즉, 퍼스널트레이닝이 유행하는 것도 이러한 현상과 무관하지 않다.

그러므로 앞으로 임상운동에서는 심장질환이나 대 사성질환은 물론 장애인 및 노인 환자 그리고 근신경 계 질환자 등 특히 움직임에 제한을 받는 환자를 대 상으로 한 프로그램에 관심을 가질 필요성이 있겠다.

한편, 이 연구에서 운동사의 직무내용을 구체화하 고 미래지향적인 엄부범위를 설정하기 위하여 국내외 유사 자격제도의 직무내용을 조사 분석하였다.
건강운동관리사의 경우 업무범위와 직무내용을 살 펴볼 때 $\mathrm{ACSM}$ 의 엑서사이스 피지올로지스트(구, 헬 스 피트니스 스페셜리스트) 혹은 NSCA-CSCS에 준하 는 자격으로 발전될 수 있다고 사료된다. 그러나 법률 적 한계와 현재의 시험 내용이나 직무연수 내용을 고 려할 때 $\mathrm{ACSM}$ 의 크리니컬 피지올로지스트 혹은 NATA-ATC 자격과는 상당한 차이가 있을 수밖에 없 다. 결과적으로 체육지도자가 임상이나 스포츠현장에 서 의료인들과 협업할 수 있는 법적인 보장을 받지 못하게 됨으로써 업무의 한계가 있을 수밖에 없다고 사료된다. 체육계는 이 부분을 제도적으로 커버하기 위해 상당한 노력을 기울였지만 건강운동관리사는 그 태생이 과거 "1급 생활체육지도자"를 모체로 출발하 였기 때문에 업무범위를 확대하는 일이 쉽지 않았을 것이고 또한 국가자격인지라 법 개정 과정에서 타 부 처의 의견을 무시할 수 없었던 상황에서 관련부처와 의 협조가 쉽지 않았을 것으로 사료된다.

그러나 <Table 1, 2>에서 보는 바와 같이 한국에서 운동사 수요는 헬스/피트니스 아니면 병원에서 많이 일어나고 있으며 요구되는 업무내용은 주로 근골격계 질환 및 운동손상 관리를 위한 교정운동을 포함한 치 료적 운동이나 재활 운동이 주종을 이룬다는 사실을 간과할 수 없다. 또한 운동사든 건강운동관리사든 체 육지도자는 병원이 아니라 주로 체육·스포츠 현장에 서 일하고 있으며 더욱이 이 같은 운동을 필요로 하 는 사람들이 병원보다 병원 밖에 더 많다는 사실로 미루어 볼 때, 건강운동관리사의 업무범위에서 신체교 정운동과 재활훈련이 제외된 것(Ministry of Culture, Sports and Tourism, 2014)은 체육지도자의 일자리와 맞물린 중대한 사안임을 관계 부처는 인식해야 할 것 이다.

앞으로 체육진흥법시행령(Ministry of Culture, Sports and Tourism, 2014)에서 "의료기사 등에 관한 법률 시행령」제 2 조 제 1 항 제 3 호의 신체교정운동 및 재활 훈련은 제외한다."라고 업무제한을 둠으로써 건강운동 사의 취업에 상당한 지장이 초래되거나 타 직종과의 갈등이 빗어질 가능성이 있다고 사료된다.

의료기사 등은 의료기관에서 일하는 사람들이다. 의사가 운동이 필요하다고 판단되는 환자들을 병원밖 에 있는 운동사 등에게 의뢰해서 체육시설에서 운동 
을 하도록 하는 경우에 의료기사를 딸려 보낼 수는 없다. 그리고 교정운동이나 재활훈련은 운동 목적이나 용도에 따라 편의적으로 분류한 용어로서 운동의 성 격이나 형태가 건강체력 분야에서의 운동과 크게 다 르다고 하기 어렵다. 운동사 등이 개발한 다양한 운동 은 대상자의 상태에 맞게 적절히 적용되는 것이기 때 문에 서전에 용도나 목적을 명확한 구분을 짓기도 어 렵다. 그러므로 이 같은 조항은 건강운동관리사의 업 무를 제한하는 불필요한 규제로서 시급히 개선돼야 할 문제이다. 만약 부처 간의 이견을 좁히지 못해 이 문제를 해결하지 못한다면 다른 선진국과 같이 민간 에서라도 해결책을 찾아야 할 것이고 그 대안이 운동 사 등이 될 수밖에 없다(Oak \& An, 2012).

이 같은 입장에서 운동사는 운동손상관리와 스포츠 재활, 나아가 다양한 임상운동 프로그램을 더욱 심도 있게 개발해 나가야 할 것이다. 하지만 운동사 등의 양성은 대학교육이 담당해야 하는 만큼 교육의 질적 고도화 및 내실화를 위해서 대학의 교과과정을 개선 하는 일이 시급하다(Jung, 2006).

이 연구의 조사결과, 전국에서 운동사 양성을 목표 로 하는 대학으로서 12 개 대학의 체육계열학과인 것 으로 나타났다.

이들 대학의 교과과정을 분석한 결과 일반 체육계 열 학과와는 달리 인문사회 교과목 비중이 낮음을 알 수 있었고 반대로 건강과 관련된 교과목이나 운동사 로서 필수적으로 갖추어야 할 이론이나 실기능력을 배양할 수 있는 교과목을 우선적으로 선택하고 있음 을 알 수 있었다. 기존의 교과과정 틀 속에서 교수중 심의 교과목을 개설한 흔적이 보이고 건강체력 분야 의 교과목으로 분류된 것 중에서 운동사 양성에 불필 요한 교과목도 상당수 포함돼 있는 것으로 사료된다. 또한 교과목 너무 세분됨에 따라 학점수가 3학점 미 만인 과목이 많아 체계적이고 일관성 있는 교육이 이 루어지기 힘든 측면이 없지 않다고 사료된다. 교과목 명칭도 통일돼 있지 않고 올바른 영문표기도 시급히 개선되어야 할 문제이다.

<Table 1>과 <Table 2>에서 살펴본 바와 같이 운 동사의 진로나 취업 방향이 보건의료기관이나 스포츠 재활 업무 중심으로 진행되고 있음에도 불구하고 의 학적 기본지식과 운동손상평가, 치료적 운동 등에 교
과목 비율이 낮다고 사료된다. 교과목의 성격들을 비 교해 볼 때 운동사의 진로와 관련된 체계적인 교과과 정의 구성을 위한 많은 노력이 필요해 보인다. 또한 운동사 양성을 목표하지만 이들이 나아가 현장에서 어떤 일을 어떻게 해야 하는지에 대한 연구와 그러한 일을 하려면 어떤 것을 배워야 하는지에 대한 진지한 토론이 있어야 할 것으로 사료된다. 앞으로 운동사 양 성으로 목표로 하되 이들이 수행하는 직무를 세밀히 분석하고 체계화함으로써 필요한 교과목 설정 및 학 년별 수강절차를 구성하는 교과과정 로드 맵을 구성 할 필요가 있겠다.

이와 같이 앞으로 교과과정을 비롯한 전반적인 교 육과정이 운동사 자격제도를 뒷받침할 수 있는 대학 들이 늘어난다면 이들 대학 졸업자들에게 한하여 운 동사 자격시험 응시자격을 부여하는 방안이 검토될 수도 있을 것이다.

전문가회의를 통해 나타난 특징적 지적사항은 건강 운동관리사의 직무연수 기간이 너무 길다는 사실이었 다. 이에 따른 대학의 기능에 의문도 제기 되었다.

대학을 졸업하는 학생들은 현장에 나가 실질적인 직업 활동을 수행할 수 있어야 한다. 더욱이 현장에서 요구하는 인재를 양성하기 위해서 대학에서는 실습교 육을 더욱 충실히 해야 할 것이며 이에 필요한 과목 을 보완되어야 할 것으로 사료된다. 이 같은 대학의 역할을 고려할 때 건강운동관리사가 국가자격으로서 시험 후 장기간에 걸쳐 직무연수를 시행하는 것은, 현 장실습을 위한 것이라 하지만, 현실적으로 목적달성이 쉽지 않을 것으로 사료된다. 오히려 대학에서 그러한 기능을 할 수 있도록 지침을 주고 응시자격이나 시험 에서 이를 검증하는 것이 바람직하다고 본다. 그래야 대학이 제대로 기능할 수 있고 국가자격제도가 대학 교육을 바로 세울 수 있는 긍정적인 효과를 가져다 줄 수 있다고 사료된다.

아울러 성공적인 자격제도의 운용을 위해서 운동사 가 되고자 하는 학생들이 학교에서 어떤 교육을 어떻 게 받아야 하는지에 대한 지침이 체계적으로 그리고 구체적으로 제시되어야 할 것이다. 


\section{결론 및 제언}

운동사의 사회적 수요는 스포츠 관련 시설보다는 보 건의료기관에서 더 많이 나타나고 있지만, 주로 근골격 계를 중심으로 하는 치료적 또는 재활 운동 지도가 주 요업무로 요구되고 있었다. 내과적 환자를 대상으로 하 는 임상운동이나 운동선수재활을 위해 운동사를 구하 는 경우는 아직 크게 확산되고 있지 않고 있다.

국내외 유사자격지도와 업무내용을 비교해 볼 때 국가자격인 건강운동관리사의 업무가 건강체력 분야 에 치중되고 의사로부터 의뢰된 환자들의 운동교육을 담당한다고는 하지만 신체교정운동 및 재활훈련 등이 업무에서 제외됨으로써 업무에 한계가 있음이 지적되 었다. 건강운동관리사의 직무연수 기간이 너무 길다는 것이 문제점으로 지적되었다. 그러므로 그 대안으로서 운동사는 임상운동은 물론, 운동손상 및 스포츠재활 등의 업무 능력을 길러 다양한 현장에서 의료진과 협 업할 수 있도록 능력배양에 힘써야겠다.

이와 같은 방향에서 운동사를 양성하는 대학에서는 다음과 같은 방향에서 교과과정의 개선이 요구된다.

첫째, 취업을 목표로 하는 현장중심의 교과과정 로 드맵을 구성한다.

둘째, 운동사의 역할수행에 공통적으로 중요한 교 과목은 필수과목으로 지정한다.

셋째, 의학적인 기본지식을 쌓을 수 있는 교과목을 보강한다.

넷째, 운동손상평가, 치료적 운동, 재활 운동, 각종 현장실습 등의 교과목을 보강한다.

한편, 교과목의 국·영문 명칭과 현장실습 지침이 국가적으로나 관련 학회를 중심으로 시급히 마련되어 야 할 것이다.

\section{참고문헌}

ACSM (2015). Certification. Retrieved October 10 from http://certificationacsmorg/get-certifi ed. CHA University (2015). Curriculum. Retrieved September 10 from http://sports.cha.ac.kr/.
Daegu University (2015). Curriculum. Retrieved October 10 from http://health.daegu.ac.kr/.

Dankook University (2015). Curriculum Retrieved September 10 from http://cms.dankook.ac.kr/web/spo rtsscience/-9.

Dongshin University (2015). Curriculum. Retrieved September 10 from http://exercise.dsu.ac.kr /sub010200.

Jeonju Univesity (2015). Curriculum Retrieved September 10 from http://www.jj.ac.kr/juep/schoolaffa ir/course.jsp.

Jung D. J. (2006). Education curriculum and equipment of the specialized college and university related with exercise prescription KINESIOLOGY, 8(2): 63-73.

Jung D. J. (2013). Exploring the role of a personal trainer(exercise professional). KINESIOLOGY, 15(1): 157-173.

KACEP (2015). Recruit. Retrieved September 302015 from www.kacep.or.kr.

Konyang Univiersity (2015). Curriculum. Retrieved September 10 from http://www.konyang.ac .kr/prog/curriculum/kor/sub03_06_07_03/s ports/view.do.

Korea National Sport University (2015). Curriculum. Retrieved September 10 from http://www. knsu.ac.kr/web/health/p_01.

Kyunghee University (2015). Curriculum. Retrieved

September 10 from http://sports.khu.ac.kr/ html_2010/04/02_06.php.

Ministry of Culture, Sports and Tourism (2013). The reform plan for physical education leader qualifications Seminar.

Ministry of Culture, Sports and Tourism (2014). National Sports Promotion ACT Retrieved December 31 from http://www.law.go.kr.

Namseoul University (2015). Curriculum. Retrieved September 10 from http://www.nsu.ac.kr/ m03/?s=02_06\&mode $=C$.

NATA (2015). Certification. Retrieved October 10 
from http://www.bocatc.org/index.php.

NSCA (2015). Certification. Retrieved on October 10 from https://www.nsca.com/certification/.

Oak J. S. \& An, K. O. (2012). A Study for Enacting of "the Rules on Kinesiologist". KINESIOLOGY, 14(1): 77-88.

Role Delineation Study (2009). 6th ed. Omaha, NE: Board of Certification.

Soonchunhyang University (2015). Curriculum. Retrieved on September 10 from http://homepage.schac .kr/schsm/02/01.jsp.

Sungshin Women's University (2015). Curriculum. Retrieved September 10 from http://www. sungshin.ac.kr/exercise/.

Woosong University (2015). Curriculum. Retrieved September 10 from http://rehab.wsu.ac.kr/ page/index.jsp?code=rehab0103. 
